\title{
The Vacuum System for Insertion Devices at the Advanced Photon Source*
}

\author{
E. Trakhtenberg, E. Gluskin, P. Den Hartog, T. Klippert, G. Wiemerslage, and S. Xu, \\ Argonne National Laboratory, 9700 S Cass Avenue, Argonne, IL 60439 USA
}

\section{Abstract}

A vacuum system for the insertion devices at the Advanced Photon Source was designed, and chambers of this design were successfully manufactured and tested. Three different versions of the vacuum chamber have been developed with vertical apertures of $12 \mathrm{~mm}, 8 \mathrm{~mm}$, and $5 \mathrm{~mm}$, respectively. The chambers are fabricated by extruding 6063 aluminum alloy to form a tube with the desired internal shape and machining the exterior to finish dimensions. The wall thickness of the completed chamber at the beam orbit position is $1 \mathrm{~mm}$. The design utilizes a rigid strongback that limits deflection of the chamber under vacuum despite the thin wall. Chambers with lengths of $2.2 \mathrm{~m}$ and $5.2 \mathrm{~m}$ have been fabricated. Pumping is accomplished by a combination of lumped and distributed nonevaporable getters and ion pumps. An ultimate pressure of $5.1 \cdot 10^{-11}$ torr was achieved with the $12-\mathrm{mm}$ vertical aperture prototype. Alignment of the vacuum chamber on its support stand can be made with a precision of $\pm 25 \mu \mathrm{m}$ in the vertical plane, which allows minimum insertion device pole gaps of $14.5 \mathrm{~mm}, 10.5 \mathrm{~mm}$, and $7.5 \mathrm{~mm}$.

\section{INTRODUCTION}

In order to meet requirements for the integration of the insertion device vacuum chamber (ID VC) as a part of the APS storage ring and to optimize the insertion device performance, the ID VC design must meet the following technical specifications:

\begin{tabular}{|l|l|}
\hline $\begin{array}{l}\text { vacuum pressure } \\
\text { (e+beam off) }\end{array}$ & $<2 \times 10^{-10}$ \\
\hline $\begin{array}{l}\text { vacuum pressure } \\
\text { (e+beam on) }\end{array}$ & $<1 \times 10^{-9}$ \\
\hline horizontal aperture & $51 \mathrm{~mm}(40 \mathrm{~mm})(30 \mathrm{~mm})$ \\
\hline vertical aperture & $12 \pm .2 \mathrm{~mm}(8 \pm .2 \mathrm{~mm})(5 \pm .2 \mathrm{~mm})$ \\
\hline $\begin{array}{l}\text { min VC wall } \\
\text { thickness }\end{array}$ & $1 \pm .1 \mathrm{~mm}$ \\
\hline $\begin{array}{l}\text { total budget of } \\
\text { "unflatness" over } \\
\text { the 5.2 meter } \\
\text { length }\end{array}$ & $.5 \mathrm{~mm}$ \\
\hline
\end{tabular}

The vacuum wall thickness and the flatness are driven by the requirements of the insertion device performance at minimum magnetic gap.

While the vacuum requirements for the ID VC are the same as for the rest of the storage-ring vacuum system, the requirements for the mechanical structure are quite different. In particular, the vertical and horizontal apertures are much smaller than those for the SR VC. Also, the tight flatness tolerances must be met along the entire 5.2-meter length of the thin-walled ID VC. The SR VC does not require such tight flatness tolerances [1]. In order to meet these specifications, a new cross section (Fig. 1) for the ID VC was designed. The new design is based on an approach termed "tolerances guidance," in which the thin-walled part of the ID VC will follow the thick body of the rest of the ID VC in all its deviations from a straight line.

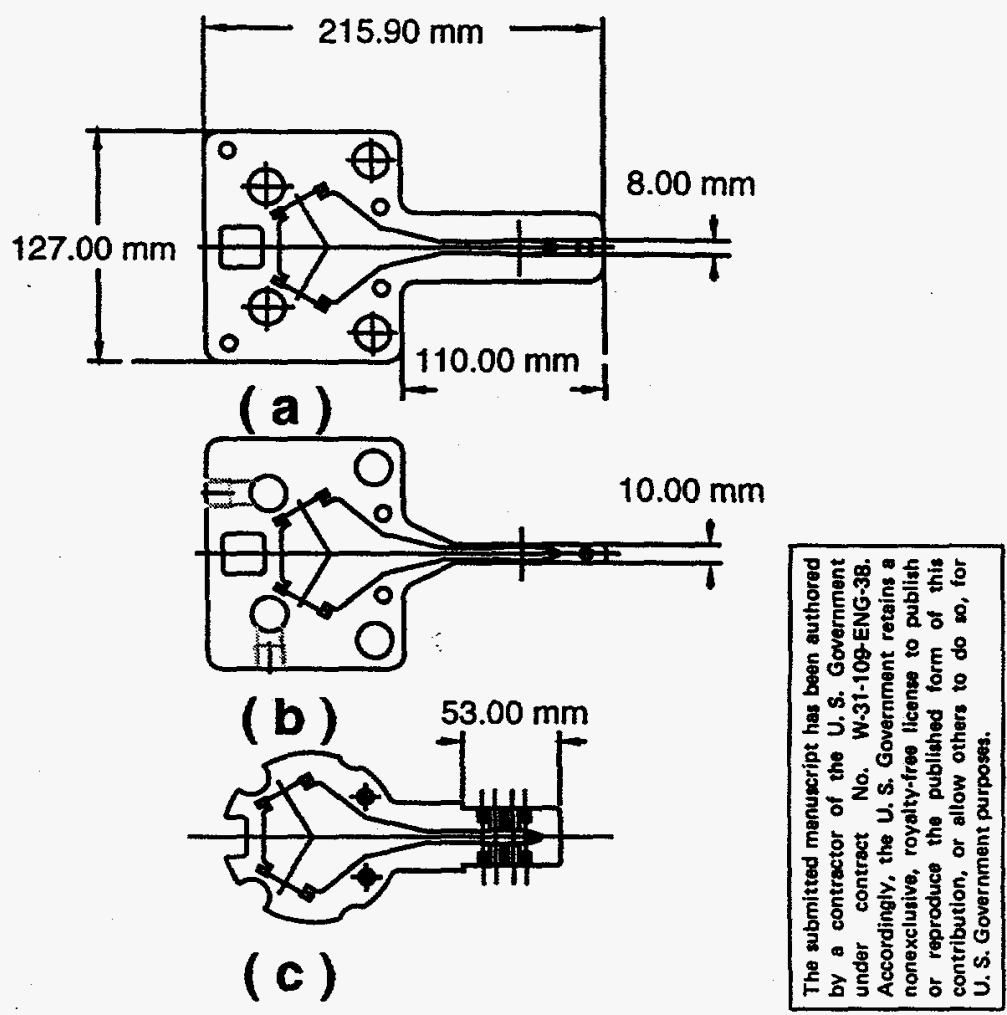

Figure 1. Cross-section of the 8-mm ID vacuum chamber. a) extrusion, b) after machining, c) end geometry showing the locations of beam position monitors.

\section{FABRICATION}

The manufacturing process for the ID VC consists of two major steps: an extrusion and a subsequent machining. The ID $\mathrm{VC}$ is extruded from the aluminum alloy $6063 \mathrm{~T} 6$ (as is the SR VC). The complicated pattern of this cross section results from the following requirements: first, uniform material flow in the extrusion process; second, rigidity of the ID VC with and without atmospheric pressure, and third, compatibility with thin-walled machining. The most critical dimension of the cross section is the opening on the right side where the positron beam moves through the ID magnetic field. The maximum deviation from the nominal dimension of $12 \mathrm{~mm}$ did not exceed $50 \mu \mathrm{m}$ for 5 randomly selected extruded ID VCs. The machining brings the outside dimension down to $14 \mathrm{~mm} \pm 100 \mu \mathrm{m}$ along the 5.2-meter length.

*Work supported by U.S. Department of Energy, Office of Basic Energy Sciences, under Contract No. W-31-109-ENG-38. 


\section{DISCLAIMER}

This report was prepared as an account of work sponsored by an agency of the United States Government. Neither the United States Government nor any agency thereof, nor any of their employees, makes any warranty, express or implied, or assumes any legal liability or responsibility for the accuracy, completeness, or usefulness of any information, apparatus, product, or process disclosed, or represents that its use would not infringe privately owned rights. Reference herein to any specific commercial product, process, or service by trade name, trademark, manufacturer, or otherwise does not necessarily constitute or imply its endorsement, recommendation, or favoring by the United States Government or any agency thereof. The views and opinions of authors expressed herein do not necessarily state or reflect those of the United States Government or any agency thereof. 


\section{DISCLAIMER}

Portions of this document may be illegible in electronic image products. Images are produced from the best available original document. 


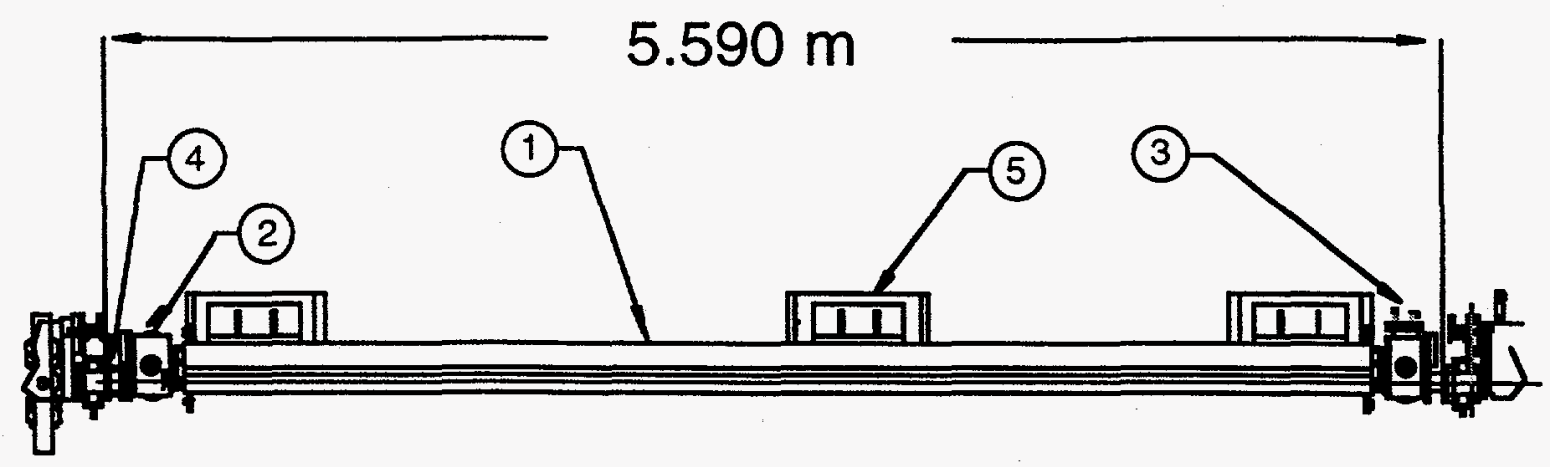

Figure 2. Layout of the $5 \mathrm{~m}$ ID vacuum chamber. 1) ID chamber, 2) 3) stainless steel end box,

4) bellows, 5) support structure

An insertion-device vacuum system with a total length of $5590 \mathrm{~mm}$ will occupy an Advanced Photon Source (APS) storage ring straight section. Two configurations for the insertion-device vacuum system have been designed. The primary configuration will accommodate two insertion devices while the secondary will accommodate only one device in the APS straight section. We intend to use the secondary configuration only during the commissioning or where no future need for two insertion devices is foreseen. [2] The general layout of the first configuration is shown in Fig. 2.

The insertion devices vacuum system is placed between two UHV, all-metal valves. The ID VC is supported by three rigid stands equipped with alignment screws. Threaded holes with stainless steel inserts are used to attach the chamber to the brackets of the support stands. The total deviation of the thinwalled part of the vacuum chamber from the plane surface does not exceed $50 \mu \mathrm{m}$ when it is installed on the support. During tests this alignment was maintained during hundreds of hours of observation in a room with a temperature variation of more than $2^{\circ} \mathrm{C}$.

In order to achieve and control the required vacuum, the ID $\mathrm{VC}$ is equipped with a set of vacuum pumps and vacuum gauges. The total pumping capacity is achieved by combining two -5 meter-long non-evaporable getter (NEG) strips with an average pumping speed of $\sim 6 \mathrm{~V} /(\mathrm{sec} \mathrm{cm})$, a $30 \mathrm{~V} / \mathrm{sec}$ ion pump, and a $220 \mathrm{l} / \mathrm{sec}$ lumped NEG pump in each end box. The calculated results for the chosen geometry and pumping capacity are presented in Fig. 3 [3].

In addition to the pumps, the end boxes (Fig.4) also accommodate transition sections, an $x$-ray absorber, and vacuum analyzers. The transition section in the upstream box is a water-cooled copper block that provides a smooth transition between the aperture of the ID and SR vacuum chambers. The transition block in the downstream box is not water cooled. Both transition sections must be installed to avoid impedance mismatches which would effect the positron beam. The $x$-ray absorber is located in the downstream end box. It prevents the bending magnet synchrotron radiation from penetrating the vacuum valve. Thermal calculations show that, under relatively moderate cooling conditions, the temperature rise on the surface of the transition block or on the $x$-ray absorber does not exceed $110^{\circ} \mathrm{C}$ with a $300-\mathrm{mA}$ positron current in the storage ring and under maximum $\mathrm{x}$-ray beam mis-steering.
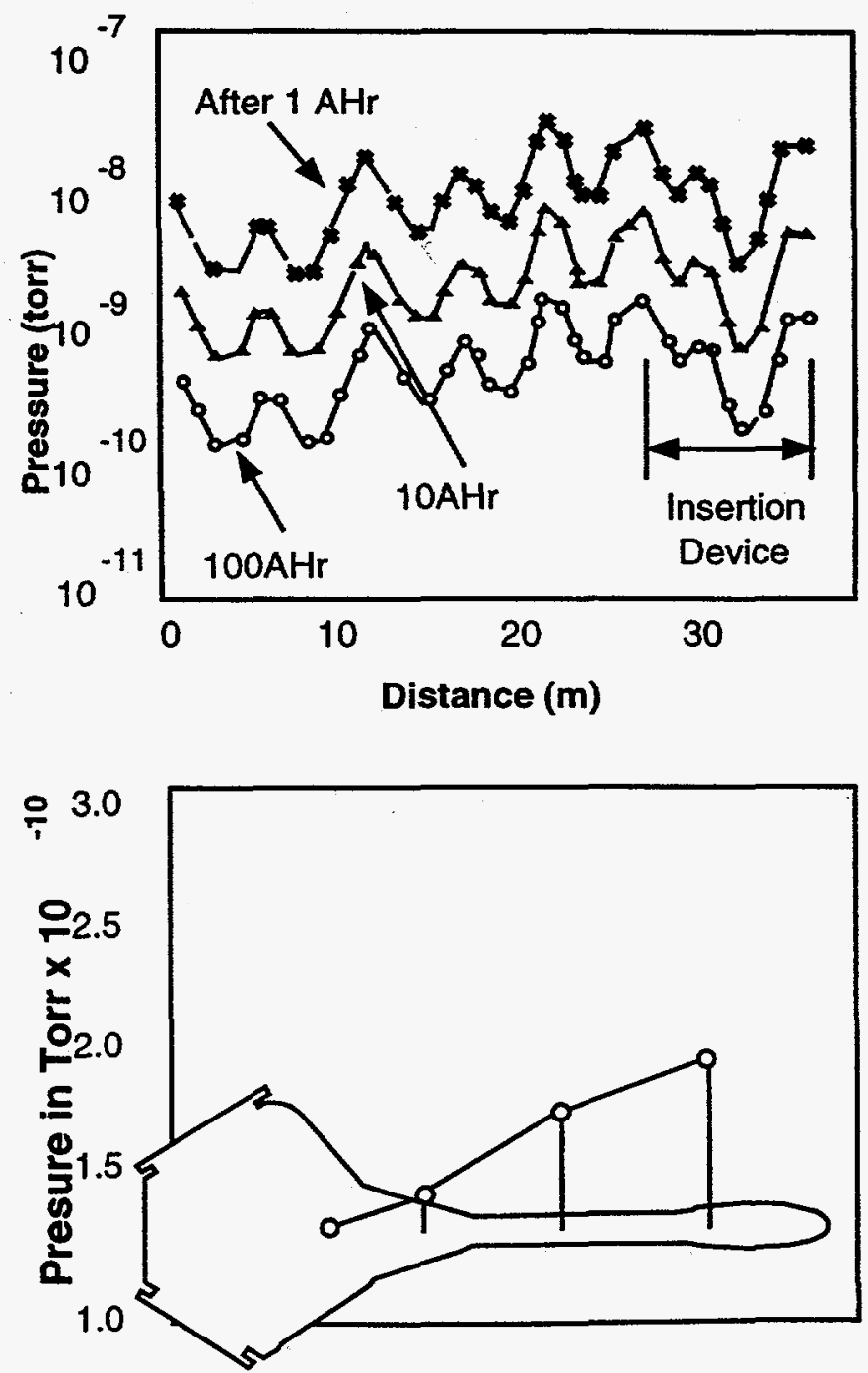

Figure 3. Pressure profile of storage ring sector showing the position of the insertion device vacuum chamber (top) and pressure profile within the $12 \mathrm{~mm}$-aperture chamber. 
One of the walls in each end box is made of a bimetal rollbonded composite of stainless steel and aluminum alloy to simplify the welding of the end boxes to the vacuum chamber.

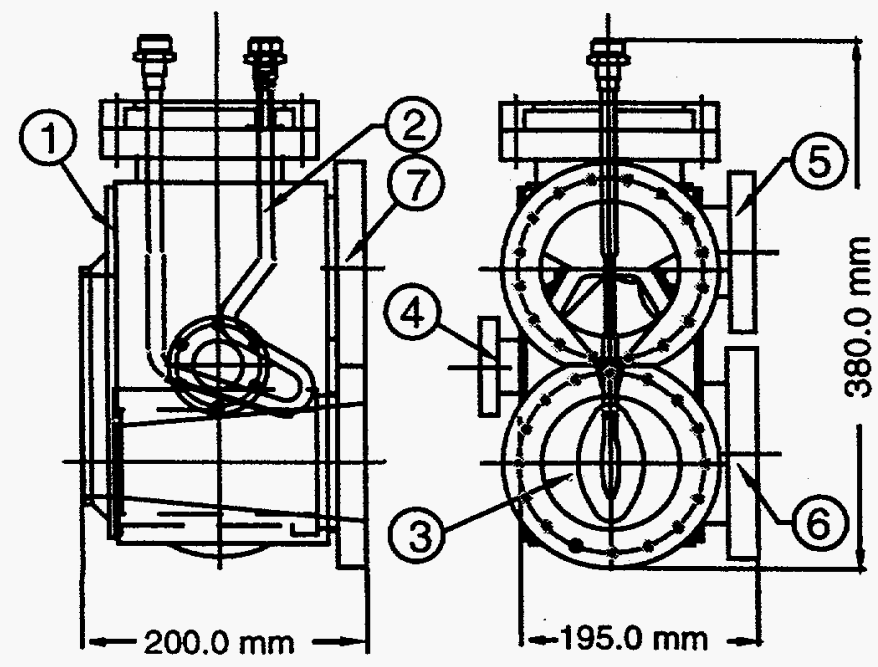

Figure 4. Vacuum end box. 1) bimetallic wall, 2) x-ray absorber, 3) rf transition, 4) diagnostic port, 5) and 6) pumping ports, 7) NEG feedthrough port.

Each vacuum chamber is machined to provide a smooth transition from the chamber aperture to the $12 \mathrm{~mm}$ aperture of the end box. This enables the use of a single end box design for the three different apertures of vacuum chambers.

In summary, the ID VC manufacturing procedure consists of the following set of steps:

1) extrusion of the 6-meter-long chamber with subsequent stretching to remove twist and bow;

2) additional straightening on a hydraulic press before machining;

3) machining the final cross section and to ready the ends for welding; also, machining of the precision platforms for the beam position monitor placement on both ends of the chamber;

4) manufacturing of both end boxes (in parallel);

5) welding the boxes to the vacuum chamber on an automatic welding machine.

Before welding the end boxes are cleaned and baked in a vacuum furnace at a temperature of up to the 300 degree $C$, followed by a leak test. After welding the whole vacuum chamber undergoes a thorough second cleaning[3], leak test, bakeout, and certification.

\section{TESTING AND RESULTS}

The standard baking procedure, including the NEG strip activation, usually takes three-four days after which the final pressure in the ID VC is $\leq 2 \times 10^{-10}$ Torr. To date, we have finished manufacturing, assembly, and certification of $7 \mathrm{ID}$ VCs.

The measured maximum deflection of the thin-walled part of the ID VC under atmospheric pressure did not exceed $35 \mu \mathrm{m}$ on each wall for the $12 \mathrm{~mm}$ and the $5 \mathrm{~mm} \mathrm{VC}$ and about 50 microns for the $8 \mathrm{~mm}$ VC. These measurements are in a good agreement with the ANSYS calculations. The deflection increased only slightly, about $10 \mu \mathrm{m}$, after the bakeout and did not change afterwards. As mentioned above, the "straightness" specification was exceeded by an order of a magnitude; allowing smaller gaps of the APS insertion devices and extending their capabilities[4]. The ultimate vacuum achieved in ID VC was $5.1 \times 10^{-11}$ torr. Hydrogen dominates in the residual gas spectrum in good agreement with the calculations and expectations.

There are at least two alternative approaches to the design of a small vertical aperture ID VC. One is to use a the thin wall flexible stainless steel VC which is more expensive and also is much bulkier, especially on the ends. The other is to use a welded stainless steel VC as has been built at ESRF but it is very difficult to achieve the required flatness.

\section{ACKNOWLEDGMENTS}

The authors are grateful to J. Noonan, G. Goeppner and G. Gagliano for their very valuable assistance; to J. Arko, $K$. Knoerzer and T. Robertson for their substantial contribution during prototype and serial manufacturing assembling and testing; to R. Piech for his contribution to the design.

1 G.A. Goeppner, "APS Storage Ring Vacuum Chamber Fabrication," American Institute of Physics Conference Proceedings No. 236, American Vacuum Society, Series 12, Argonne, IL 1990.

2 E. Trakhtenberg, E. Gluskin, and S. Xu, "The Vacuum System for Insertion Devices at the Advances Photon Source," Rev Sci, Instrum.,66, No. 2, Part 2, Feb 1995.

3 Chian Liu and John Noonan, "Advanced Photon Source Accelerator Ultrahigh Vacuum Guide," ANL/APS/TB-16, March 1994.

4 R. Dejus, B. Lai, E. Moog, and E. Gluskin, "Undulator A Characteristics and Specifications: Enhanced Capabilities," ANL/APS/TB-17, May 1994. 